0

GeOrge Fox

UNIVERSITY
Digital Commons @ George Fox University

Faculty Publications - School of Physical

Therapy

School of Physical Therapy

2020

Preseason Y Balance Test Scores are Not Associated With a

Lower Quadrant Sports Injury in a Heterogeneous Population of

Division III Collegiate Athletes

Jason Brumitt

Jill A. Sikkema

Saiko Mair

CJ Zita

Victor Wilson

See next page for additional authors

Follow this and additional works at: https://digitalcommons.georgefox.edu/pt_fac

Part of the Physical Therapy Commons 


\section{Authors}

Jason Brumitt, Jill A. Sikkema, Saiko Mair, CJ Zita, Victor Wilson, and Jordan Peterson 


\title{
Preseason Y Balance Test Scores are Not Associated With a Lower Quadrant Sports Injury in a Heterogeneous Population of Division III Collegiate Athletes
}

\author{
Jason Brumitt, PT, PhD, ATC, CSCS,1 Jill Sikkema, EdD, ATC,1 Saiko Mair, MS, ATC,1 CJ Zita, DPT,1 \\ Victor Wilson, DPT,12 and Jordan Petersen, DPT1 \\ 1George Fox University; 2ATI Physical Therapy
}

\begin{abstract}
Functional performance tests, such as the Y Balance Test-Lower Quarter (YBT-LQ), hold promise as screening tools to identify athletes at risk for injury. The ability of the YBT-LQ to discriminate injury risk in Division III collegiate athletes is unknown. The purpose of this study was to determine if preseason YBT-LQ scores are associated with noncontact time-loss lower-quadrant (low back or lower extremities) injury in a heterogeneous population of Division III collegiate athletes. Two hundred and fourteen athletes (females $=104$ ) performed the YBT-LQ test. Preseason YBT-LQ scores, analyzed by the total population, were not associated with noncontact time-loss lower-quadrant injury. Females with greater reach scores in some directions did have a significantly greater risk of injury. This study adds to a growing body of research demonstrating that the YBT-LQ should not be used as a preseason screening tool.
\end{abstract}

Keywords: functional performance test, lower extremity, preseason screening, prospective cohort

Nearly 200,000 student-athletes compete in sport at the National Collegiate Athletic Association (NCAA) Division-Ill (D-III) level.1 Student-athletes who partici pate in sport at the D-III level report physical, emotional, social, and academic benefits. 2 However, those who

\section{Key Point s}

A recent trend in sports medicine

- research is to identify athletes at risk for injury based on preseason performance profiles.

One functional performance test, the Y Balance Test-Lower Quarter, has shown promise as a preseason screening tool.

The ability of the $Y$ Balance TestLower Quarter to discriminate injury

$\wedge$ risk in a heterogeneous population of Division III collegiate athletes is unknown. participate in sport are at risk for injury. Male athletes competing at the D III level experience 6.5 time-loss injuries per 1,000 athletic exposures (AE).3 Female athletes experience 4.7 timeloss injuries per 1,000 AE.3 A sports injury to a D-IH athlete may negatively impact one's studies, increase one's stress, result in numerous medical and rehabilitation ap pointments, and affect the athlete's team's success.4-10 Therefore, identifying ath letes at risk for injury may help sports medicine profes sionals and coaches to inter vene with training programs to reduce one's risk of sustaining a sport-related time-loss injury.

The Y Balance Test is a functional performance test (FPT) designed to assess dynamic balance.11-14 It is an

Brumitt is an associate professor of Physical Therapy, George Fox University, Newberg, OR. USA. Sikkema and Mair are assistant athletic trainers with George Fox University, Newberg, OR, USA. Zita, Wilson, and Petersen are physical therapists with George Fox University, Newberg, OR, USA. Wilson is now with ATI Physical Therapy, Beaverton, OR, USA. Brumitt (jbrumitt@georgefox.edu) is corresponding author. instrumented device with three extensions from its weightbearing platform in the shape of a Y.11 The Y Balance Test-Lower Quarter (YBT-LQ) shape was de signed based on the results from a prospective cohort study that employed the use of the Star Excursion Balance Test (SEBT). 12 When performing the YBT-LQ, subjects are asked to maintain single-leg support with one lower extremity (LE) while simultaneously sliding the reach indicator along the anterior, posteromedial, or the pos terolateral axis with the non-weightbearing LE.1

Initial studies reported an association between preseason YBT-LQ performance and future time-loss LE injury. Plisky et al.12 prospectively measured reach performance with the SEBT (the precursor to the YBT-LQ) in a population of high school basketball (BB) players $(n=235)$ prior to the start of their season. High school BB players who presented at the start of the season with an anterior reach asymmetry greater than $4 \mathrm{~cm}$ had a 2.5 -fold increased risk of having a time-loss LE injury during the season. 12 Female BB players $(n=105)$ with a composite reach score (a mea sure based on the distance reached in each component of the Y pattern) that was less than $94 \%$ of their LE length had a 6.5 -fold increased risk of LE injury during the season.12 Smith et al.15 found that an anterior asymmetry $>4 \mathrm{~cm}$ during YBT-LQ testing was associated with a two-fold increased risk of a noncontact injury, regardless of time loss, in a heterogeneous sample of Division I athletes. 15 Butler et al.16 did not find anterior asymmetry to be associated with future injury in collegiate football players; however, a composite score less than $89.6 \%$ was associated with a three-fold increased risk of a noncon tact time-loss LE injury. 16

Since those initial aforementioned reports, several other studies have investigated preseason YBT-LQ 
performance and subsequent sport-related injury in other athletic populations.17-23 The ability of the YBT-LQ test to identify athletes at risk for injury has been equivocal. Potential reasons for the equivocal findings may be due to the operational definition of what constitutes a sport-related injury, the sample size of the study, or performance modifications to the test.

The YBT-LQ has held promise as a FPT to identify athletes who may be at risk for a sport injury during a preparticipation screen. However, the equivocal findings associated with the afore mentioned studies challenges the ability of clinicians to interpret the significance of an athlete's preseason scores. Therefore, addi tional studies, using standard testing procedures and operational definitions of injury, are warranted. There are two purposes to this study. The first purpose of this study was to evaluate the ability of preseason YBT-LQ scores to discriminate injury risk in a hetero geneous population (i.e., both sexes) of D-III collegiate athletes. It was hypothesized that athletes with a larger reach score asymmetry (in any direction), or a lower normalized reach score (in any direction), or a lower composite score, would be associated with a greater risk of a noncontact time-loss lower quadrant ( $\mathrm{LQ}=$ low back and lower extremities) injury. The second purpose of this study was to evaluate the ability of preseason YBT-LQ scores to discriminate injury risk per sex. It was hypothesized that athletes, analyzed by sex, would have an increased risk of a noncontact timeloss LQ injury when presenting with a larger reach score asymme try (in any direction), or a lower normalized reach score (in any direction), or a lower composite score during a preseason screening clinic.

\section{Methods}

\section{Participants}

Two hundred and fourteen D-III athletes volunteered to participate in this study. A sample of convenience was utilized by recruiting subjects from one university setting during the 2015-2016 and 2016-2017 academic years. A heterogeneous sample of 104 females (mean age 19.2 \pm 1.2 years) consisted of athletes repre senting the following sports: soccer $(n=35)$, volleyball $(n=32)$, tennis $(n=11)$, and track \& field $(n=26)$. One hundred and ten males (mean age $19.6 \pm 1.2$ years), representing basketball $(n=24)$, soccer $(n=40)$, tennis $(n=6)$, and track and field $(n=40)$, formed the heterogeneous male cohort. The institutional review board of George Fox University approved this study. Informed consent was obtained from each subject prior to participation.

\section{Procedures}

YBT-LQ protocol. The YBT-LQ test was performed by each athlete as part of a preparticipation screening clinic at the start of each sport season. The YBT-LQ test has both excellent intra- and interrater reliability. Plisky et al.n reported an intrarater reliability of 0.85 to 0.91 and an interrater reliability of 0.99 to 1.00 . Each athlete performed a dynamic warm-up prior to performing the YBT-LQ test. The dynamic warm-up protocol was performed for a 5-min period consisting of the following active LE movements: high knee marching, forward lunging, backward lunging, walking on tip toes, and walking on heels.

An investigator provided test performance instructions fol lowed by each athlete performing six warm-up trials in each direction.11 Athletes were instructed to stand on one limb, barefoot, with their toes positioned behind the line on the YBT stance platform." After the subjects completed their warm-up trials they were instructed to "reach" into one of three directions (anterior, posteromedial, and posterolateral) using their non-weightbearing (NWB) LE to slide the reach indicator (i.e., moveable platforms associated with each arm of the Y) as far as possible.11Three trials were completed on the right first (i.e., right limb single-leg stance with left limb NWB) for the anterior reach followed by three trials on the left LE reaching into the anterior direction."' 16 After completing the anterior reach trials, the subjects performed three 3 trials each for the posteromedial and posterolateral tests alternat ing between the right and left LEs."- 16 A trial was considered a failure and repeated if the athlete was unable to maintain balance on the stance platform, slid the reach indicator incorrectly by touching the indicator outside of the red target area, failed to slide the reach indicator under control (e.g., pushing or flicking the indicator forward), or stepped on to the NWB limb."'16Each reach trial was measured in centimeters $(\mathrm{cm})$. An investigator, either the primary investigator (19 years of experience) or a co-investigator (5 years of experience) measured the distance reached for each successful trial.

Next, after a subject completed the YBT-LQ test, an investi gator measured the athlete's limb length $(\mathrm{cm})$ bilaterally. The athlete was instructed to assume a supine position on a treatment table. Limb length was measured from the anterior superior iliac spine to the distal aspect of the medial malleolus."-12 Limb length measurements were used to normalize reach distance measure ments ([reach distance/limb length] X 100).1112

Injury surveillance. The university's certified athletic trainers recorded the following information for each injured athlete: injury location (categorized by region: low back, hip, thigh, knee, leg, foot/ankle), injury diagnosis, and the mechanism of injury (e.g., noncontact or contact). The primary investigator collected injury information from the university's athletic trainers on a weekly basis. The operational definition for an injury in this study was any noncontact musculoskeletal injury to the LQ (low back or lower extremities) that occurred during a practice or game, requir ing the athlete to be removed either from that day's event or preventing the ability of one to participate in the subsequent event (i.e., time loss).

\section{Statistical Analysis}

Descriptive statistics (mean $[ \pm \mathrm{SD}]$ ) were calculated for demo graphic data (e.g., age, years in school, age starting sport) per sex. Mean $( \pm \mathrm{SD})$ reach distance scores were calculated per limb for the total population, per sex, and per injury status. Reach distance was normalized as a percentage of limb length ([reach distance/limb length] $\mathrm{x}$ 100).1112 A composite reach score, which is a measure of each distance normalized to leg length, was also calculated. The formula to calculate the composite reach score was: ([mean ante rior-!-mean posteromedial + mean posterolateral]/[limb length $\mathrm{X}$ $3]) x$ 100."' 2 Independent r-tests were performed to compare reach scores between athletes who were injured or not injured during the season. Cumulative incidence was calculated by divid ing the number of injuries by the sample population (e.g., total injuries/total population).

Statistical analysis of injury risk was performed per each sex. Receiver operator characteristic (ROC) curves were constructed per sex for each reach distance and for each composite score. The purpose of performing a ROC curve analysis is to identify a cutoff score that maximizes test sensitivity and specificity. ROC curves were constructed based on reach asymmetry into each direction of 
the $\mathrm{Y}$, normalized reach distance per each direction of the $\mathrm{Y}$, and the composite score (Figure 1). The area under the curve (AUC) associated with each ROC curve were evaluated for significance. Reach measures that were found to be significant were analyzed for potential cutoff scores that maximize sensitivity and specificity. Identified cutoff scores were used to dichotomize athletes into atrisk and reference groups. Relative risk (RR) was calculated based on group dichotomization. Statistical analyses was performed by using SPSS 24.0 (IBM Inc., Chicago, IL) for all calculations.

\section{Results}

Baseline demographic measures and sport representation for each sex is presented in Table 1. A total of 38 (19 per sex) noncontact time-loss LQ injuries occurred during this study (Table 2). Thirtyseven of the 38 injuries were traumatic in nature (e.g., sprains, strains), with one injury resulting from an overuse mechanism (medial tibial stress syndrome). The cumulative incidence of injury for the total population was 17.75 per 100 athletes, 18.2 per 100 female athletes, and 17.27 per 100 male athletes. Normalized reach distances and composite score distances for each lower extremity, dichotomized by injury status, are presented in Table 3 . There were no differences in YBT-LQ scores between injured and noninjured individuals for the total population or for male athletes. There were three reach measures that were significantly different between injured and noninjured female athletes. Injured females had significantly greater reach scores into the left (L) posteromedial, (L) posterolateral, and the (L) composite score than their noninjured female counterparts ( $p$-values $=.001, .033$, and .020 , respectively).

There were only four ROC curves that had significant AUC (Table 4): right posteromedial reach for female athletes, left posteromedial reach for female athletes, left posterolateral reach for female athletes, and the left composite score for female athletes. The cutoff scores for each of the aforementioned reach measures are presented in Table 4 . Table 5 presents the relative risk of injury for the aforementioned four reach measures. Female athletes were dichotomized into an at-risk group and a reference group; the reference group consisted of athletes with greater reach scores. Female athletes with shorter reach scores were significantly less likely to experience a noncontact time-loss LQ injury. In other words, female athletes with a greater right $(\mathrm{R})$ posteromedial reach were five times more likely to get injured $(\mathrm{RR}=5.3 ; 95 \% \mathrm{CI}: 1.3$, 21.8; $p$-value $=.008)$; were four times more likely to be injured with a greater $(\mathrm{L})$ posteromedial $(\mathrm{RR}=4.1$; 95\% CI: 1.0, 17.0; $p$-value $=.02)$ or $(\mathrm{L})$ posterolateral reach score $(\mathrm{RR}=4.2 ; 95 \% \mathrm{CI}$ : $1.8,10.3 ; p$-value $=.001)$; and three times more likely to be injured with a greater $(\mathrm{L})$ composite score $(\mathrm{RR}=3.1 ; 95 \% \mathrm{CI}$ : $1.1,8.7$; $p$-value $=.023)$.

\section{Discussion}

The purpose of this study was to determine if the YBT-LQ test could be used as a screening tool to identify D-III collegiate athletes at risk for a noncontact time-loss LQ injury. Prior studies had reported a relationship between preseason scores and injury. ${ }^{12,15-18}$ However, contrary to those studies, this study found no association between preseason YBT-LQ scores and subsequent noncontact time-loss LQ injury in a heterogeneous population (i.e., male and female athletes) of D-III athletes or in a heterogeneous sample of male athletes representing four sports. Interestingly, there were statistically significant associations between some reach scores and injury in the sample of D-III female athletes; however, contrary to our hypothesis, athletes with greater reach scores had an increased risk of injury.

As previously mentioned, female athletes with greater reach scores were significantly more likely to experience a noncontact time-loss LQ injury than female athletes with shorter reach scores. This is counter to what was hypothesized. Clinicians should view

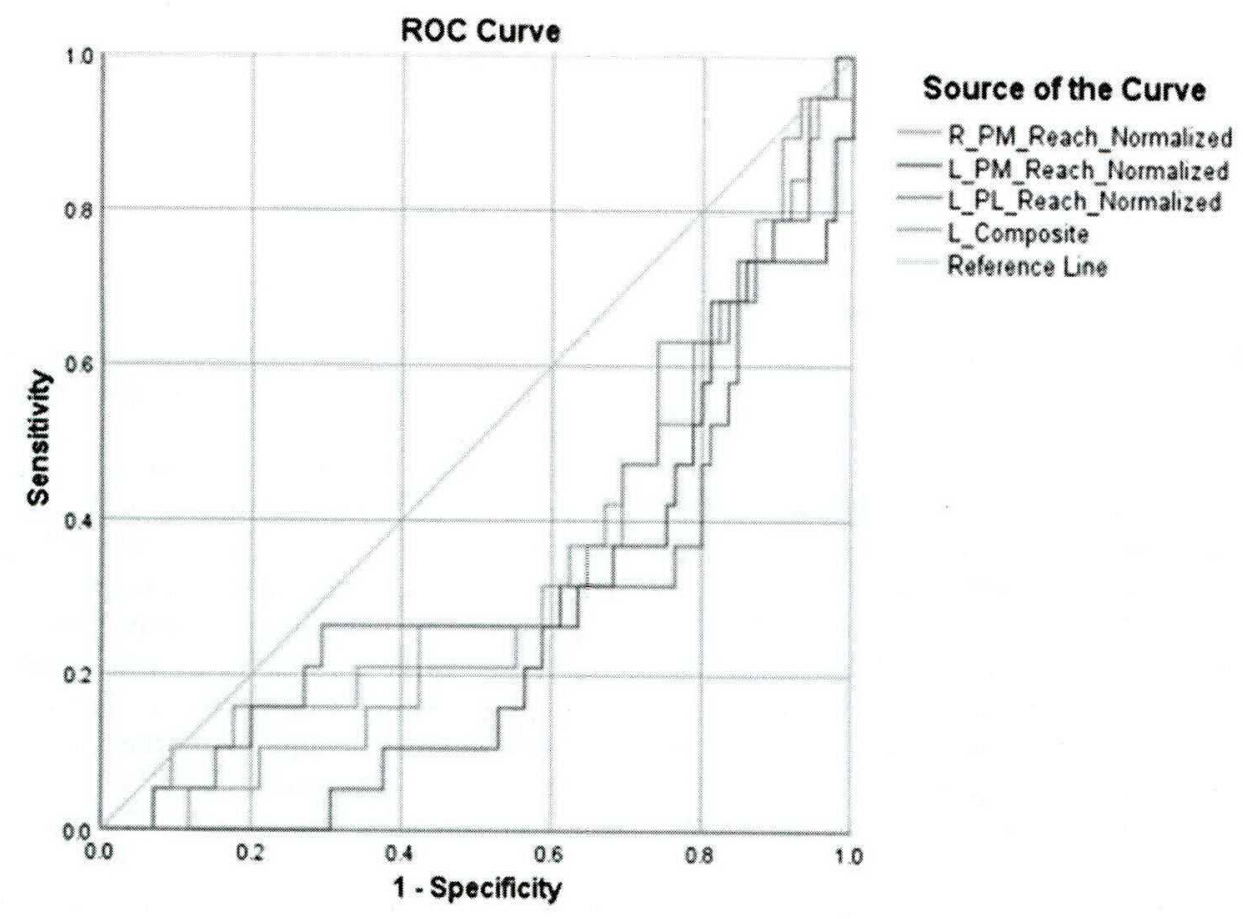

Figure 1 - Receiver operator characteristic (ROC) curves depicting significant area under the curve (AUC) for four reach measures in the female cohort (see Table 4 for entire list of reach measures evaluated by ROC curves). $R=$ right; $L=$ left; $P M=$ posteromedial; $P L=$ posterolateral. 
Table 1 Baseline Demographic Measures and Sport Representation for All Athletes and per Sex

\begin{tabular}{lccc}
\hline Characteristic & $\begin{array}{c}\text { All Athletes } \\
(\mathbf{n = 2 1 4 )}\end{array}$ & $\begin{array}{c}\text { Female Athletes } \\
(\mathbf{n}=\mathbf{1 0 4})\end{array}$ & $\begin{array}{c}\text { Male Athletes } \\
(\mathbf{n}=\mathbf{1 1 0})\end{array}$ \\
\hline Age & $19.4(1.2)$ & $19.2(1.2)$ & $19.6(1.2)$ \\
Years in school (y) & $2.1(1.1)$ & $2.2(1.1)$ & $2.0(1.1)$ \\
Age starting sport (y) & $10.5(3.6)$ & $11.1(3.0)$ & $10.0(4.0)$ \\
Sport & & & 24 \\
$\quad$ Basketball & 24 & 0 & 40 \\
Soccer & 75 & 35 & 0 \\
Volleyball & 32 & 32 & 6 \\
Tennis & 17 & 11 & 40 \\
Track \& field & 66 & 26 & \\
\hline
\end{tabular}

Table 2 Noncontact Time-Loss Injuries per Sex

\begin{tabular}{|c|c|c|}
\hline Body Region & $\begin{array}{l}\text { Females (Frequency of Injury; } \\
\text { Range of Time Loss) }\end{array}$ & $\begin{array}{l}\text { Males (Frequency of Injury; } \\
\text { Range of Time Loss) }\end{array}$ \\
\hline Torso & & Lumbar strain $(1 ; 13)$ \\
\hline Hip & $\begin{array}{l}\text { Adductor strain }(2 ; 4-12) \\
\text { Hip flexor strain }(1 ; 5)\end{array}$ & Hip flexor strain $(2 ; 6-21)$ \\
\hline Thigh & $\begin{array}{l}\text { Quadriceps strain }(2 ; 3-9) \\
\text { Hamstring strain }(5 ; 2-9)\end{array}$ & Hamstring strain $(5 ; 8-22)$ \\
\hline Knee & ACL sprain $(3 ; 36-54)$ & $\begin{array}{l}\text { Meniscus sprain }(1 ; 28) \\
\text { ACL sprain }(1 ; 65) \\
\text { PCL sprain }(1 ; 95)\end{array}$ \\
\hline Leg, ankle, foot & $\begin{array}{l}\text { Lateral ankle sprain }(4 ; 2-20) \\
\text { Medial tibial stress syndrome }(1 ; 6) \\
\text { Fibularis muscle strain }(1 ; 9)\end{array}$ & $\begin{array}{l}\text { Lateral ankle sprain }(4 ; 3-15) \\
\text { Gastrocnemius strain }(1 ; 3) \\
\text { Achilles strain }(2 ; 4-7) \\
\text { Midfoot sprain }(1 ; 7)\end{array}$ \\
\hline Total number of injuries per sex & 19 & 19 \\
\hline
\end{tabular}

Abbreviations: $\mathrm{ACL}=$ anterior cruciate ligament; $\mathrm{PCL}=$ posterior cruciate ligament.

Table 3 Comparison of YBT-LQ Preseason Scores Between Injured and Noninjured Athletes

\begin{tabular}{|c|c|c|c|c|c|c|c|c|c|}
\hline Reach Direction & $\begin{array}{c}\text { All Athletes } \\
(n=214) \\
\text { Injured } \\
(n=38)\end{array}$ & $\begin{array}{c}\text { Noninjured } \\
(n=176)\end{array}$ & $p$-value & $\begin{array}{c}\text { Female Athletes } \\
(n=104) \\
\text { Injured } \\
(n=19)\end{array}$ & $\begin{array}{l}\text { Noninjured } \\
(n=85)\end{array}$ & $p$-value & $\begin{array}{l}\text { Male Athletes } \\
(n=110) \\
\text { Injured } \\
(n=19)\end{array}$ & $\begin{array}{l}\text { Noninjured } \\
\quad(n=91)\end{array}$ & $p$-value \\
\hline \multicolumn{10}{|c|}{ Right lower extremity } \\
\hline Anterior & $69.7(6.9)$ & $69.9(9.3)$ & .884 & $69.6(4.8)$ & $68.4(7.0)$ & .492 & $69.8(8.6)$ & $71.3(10.9)$ & .565 \\
\hline Posteromedial & $111.9(15.3)$ & $108.9(16.3)$ & .288 & $109.3(17.5)$ & $101.8(18.6)$ & .110 & $114.5(12.8)$ & $115.4(10.0)$ & .726 \\
\hline Posterolateral & $109.2(12.3)$ & $107.6(10.9)$ & .407 & $109.3(10.0)$ & $106.1(10.2)$ & .231 & $109.2(14.6)$ & $108.9(11.4)$ & .922 \\
\hline Composite & $96.9(9.6)$ & $95.4(10.0)$ & .403 & $96.0(8.6)$ & $92.1(9.4)$ & .097 & $97.8(10.7)$ & $98.6(9.7)$ & .772 \\
\hline \multicolumn{10}{|l|}{ Left lower extremity } \\
\hline Anterior & $72.9(11.0)$ & $72.7(12.9)$ & .930 & $75.3(13.3)$ & $74.2(15.2)$ & .757 & $70.6(7.7)$ & $71.4(10.3)$ & .730 \\
\hline Posteromedial & $114.4(9.5)$ & $111.2(10.9)$ & .090 & $116.2(7.0)$ & $107.6(10.4)$ & .001 & $112.7(11.3)$ & $114.5(10.4)$ & .495 \\
\hline Posterolateral & $109.3(10.7)$ & $107.1(10.3)$ & .244 & $110.2(8.3)$ & $105.3(9.2)$ & .033 & $108.4(12.8)$ & $108.9(11.0)$ & .861 \\
\hline Composite & $98.9(8.3)$ & $97.0(9.1)$ & .243 & $100.6(7.2)$ & $95.7(8.4)$ & .020 & $97.2(9.2)$ & $98.3(9.5)$ & .658 \\
\hline
\end{tabular}

this finding with caution. The authors of this study are not recommending to "detrain" an athlete so that she has shorter reach scores or to have athletes with greater reach scores avoid sport participation. Rather, there are three potential reasons for this finding. First, it is possible that athletes with greater reach scores experienced more exposure to injury. For example, a study reporting YBT-LQ scores for female collegiate volleyball players $(n=134)$ found that starters had significantly greater reach scores 

Table 4 Area Under the Curve, Asymptotic Significance, Identified Cutoff Score, and Sensitivity/1-Specificity for
Each ROC Curve

\begin{tabular}{lcccc} 
Category & $\begin{array}{c}\text { Area Under the } \\
\text { Curve }(95 \% \mathrm{Cl})\end{array}$ & $\begin{array}{c}\text { Asymptotic } \\
\text { Significance }\end{array}$ & $\begin{array}{c}\text { Cutoff Score } \\
\text { per ROC }\end{array}$ & $\begin{array}{c}\text { Sensitivity/1-Specificity } \\
\text { per ROC }\end{array}$ \\
\hline ROC curve analysis based on normalized scores & & & &
\end{tabular}

All subjects $(n=214)$

(R) Anterior reach

(R) Posteromedial reach

(R) Posterolateral reach

(R) Composite score

(L) Anterior reach

(L) Posteromedial reach

(L) Posterolateral reach

(L) Composite score

Anterior reach difference

Posteromedial reach difference

Posterolateral reach difference

$\begin{array}{ll}0.493(0.399,0.587) & 0.892 \\ 0.435(0.336,0.534) & 0.207 \\ 0.467(0.362,0.573) & 0.529 \\ 0.457(0.357,0.556) & 0.402 \\ 0.471(0.376,0.565) & 0.571 \\ 0.405(0.314,0.496) & 0.067 \\ 0.434(0.330,0.538) & 0.202 \\ 0.433(0.336,0.530) & 0.196 \\ 0.565(0.469,0.660) & 0.212 \\ 0.584(0.482,0.687) & 0.103 \\ 0.588(0.485,0.692) & 0.088\end{array}$

Female subjects $(n=104)$
(R) Anterior reach
(R) Posteromedial reach
(R) Posterolateral reach
(R) Composite score
(L) Anterior reach
(L) Posteromedial reach
(L) Posterolateral reach
(L) Composite score

Anterior reach difference

Posteromedial reach difference

Posterolateral reach difference

Male subjects $(\mathrm{n}=\mathbf{1 1 0})$

(R) Anterior reach

(R) Posteromedial reach

(R) Posterolateral reach

(R) Composite score

(L) Anterior reach

(L) Posteromedial reach

(L) Posterolateral reach

(L) Composite score

Anterior reach difference

Posteromedial reach difference

Posterolateral reach difference
$0.445(0.323,0.567) \quad 0.457$

$0.346(0.205,0.487) \quad 0.037$

$0.406(0.259,0.553)$

$0.375(0.233,0.518)$

$0.410(0.279,0.540)$

$0.254(0.146,0.363)$

$0.323(0.177,0.468)$

$0.325(0.199,0.452)$

$0.510(0.369,0.651)$

$0.570(0.427,0.713)$

$0.590(0.454,0.727)$

$0.526(0.376,0.677)$

$0.522(0.365,0.678)$

$0.530(0.380,0.681)$

$0.529(0.397,0.661)$

$0.538(0.404,0.672)$

$0.525(0.378,0.672)$

$0.532(0.390,0.673)$

$0.641(0.516,0.765)$

$0.418(0.272,0.564)$

$0.591(0.433,0.748)$

0.017

0.890

0.342

0.221

0.707

0.719

0.767

0.678

0.695

0.605

0.731

0.667

0.055

0.262

0.216
$0.527(0.388,0.667)$
Not significant*

Not significant*

Not significant*

Not significant*

Not significant*

Not significant*

Not significant*

Not significant*

Not significant*

Not significant*

Not significant*

Not significant*

$$
112.66
$$

Not significant*

Not significant*

Not significant*

106.17

110.56

95.75 per ROC

Abbreviations: $(\mathrm{L})=$ left; $\mathrm{N} / \mathrm{A}=$ not applicable; $(\mathrm{R})=$ right; $\mathrm{ROC}=$ receiver operator characteristic. ${ }^{*}$ No cutoff score selected based on ROC curve analysis due to a nonsignificant area under the curve.

in five out of eight measures. ${ }^{24}$ However, in this study, $72 \%$ of the athletes who were injured were not primary starters from their team. Second, it is possible that this finding is unique to this sample and would not be validated in a second sample of female D-III athletes. Brumitt et al. observed this when prospectively evaluating injury risk based on preseason performance of the lower extremity functional test (the LEFT is an agility drill performed over a diamond-shaped course). ${ }^{25,26}$ An initial study found that faster male D-III athletes had a greater risk of a noncontact time-loss LQ injury; however, a subsequent study found no relationship between preseason scores and injury. ${ }^{25,26} \mathrm{~A}$ third potential reason is that the YBT-LQ may not be useful at dichotomizing injury risk. FPTs, such as the YBT-LQ, have held promise as screening tools to discriminate athletes at risk for injury. As previously mentioned, some studies have demonstrated an association between preseason YBT-LQ scores and subsequent injury. ${ }^{12,15-18}$ However, the findings from those aforementioned have not been validated in subsequent studies. There are several reasons that may explain why initial studies found an association between preseason dynamic balance scores and injury whereas subsequent studies have not. 
Table 5 Relative Risk of Injury Based on Reach Measures Associated With Significant ROC Curves

\begin{tabular}{|c|c|c|c|c|}
\hline Category & $\mathrm{N}$ & LQ Injury Counts and (\%) per Category & Relative Risk (95\% Cl) & $p$-value \\
\hline \multicolumn{5}{|c|}{ Females $(n=104)$} \\
\hline \multicolumn{5}{|c|}{ (R) Posteromedial reach } \\
\hline 112.66 or less & 40 & $2(1)$ & $0.2(0.05,0.8)$ & .008 \\
\hline 112.67 or more & 64 & $17(27)$ & 1.0 (Reference) & \\
\hline \multicolumn{5}{|c|}{ (L) Posteromedial reach } \\
\hline 106.17 or less & 37 & $2(5)$ & $0.2(0.05,0.9)$ & .02 \\
\hline 106.18 or more & 67 & $17(25)$ & 1.0 (Reference) & \\
\hline \multicolumn{5}{|c|}{ (L) Posterolateral reach } \\
\hline 110.56 or less & 69 & $6(9)$ & $0.2(0.1,0.6)$ & .001 \\
\hline 110.57 or more & 35 & $13(37)$ & 1.0 (Reference) & \\
\hline \multicolumn{5}{|c|}{ (L) Composite score } \\
\hline 95.75 or less & 47 & $4(9)$ & $0.3(0.1,0.9)$ & .023 \\
\hline 95.76 or more & 57 & $15(26)$ & 1.0 (Reference) & \\
\hline
\end{tabular}

Abbreviations: $\mathrm{L}=$ left; $\mathrm{LQ}=$ lower quadrant; $\mathrm{R}=$ right; $\mathrm{ROC}=$ receiver operator characteristic.

First, the operational definition (OD) of a qualifying injury used for statistical analysis varies between studies. In this study only noncontact time-loss injuries to the LQ region were counted. This OD of an injury was selected for two reasons. First, loss of time from sport is an objective measure of injury severity. The inclusion of non-time-loss injuries introduces a level of subjectivity. Smith et al. ${ }^{15}$ included non-time-loss injuries in their study. It is possible that the reported relationship between injury and anterior reach asymmetry of $>4 \mathrm{~cm}$ would not have been significant had the authors only included noncontact time-loss injuries in their analysis (Note: This is speculative, the authors ${ }^{15}$ did not report different odds ratios for only time-loss injuries). ${ }^{15}$ Second, only noncontact injuries were included in the analysis. There is evidence in the literature that the risk of experiencing a noncontact injury (e.g., hamstring strains, noncontact anterior cruciate ligament sprains) may be reduced with training programs. ${ }^{27-30}$ To our knowledge there is no evidence that suggests injuries due to contact mechanisms can be reduced with training programs. One prospective cohort study evaluating the ability of the YBT as a screening tool included injuries resulting from a contact mechanism. Hartley et al. ${ }^{18}$ reported that a shorter anterior reach score was associated with an ankle sprain. It is possible that they would not have reported a significant association between scores and injury had they only included injuries resulting from noncontact mechanisms (Note: This is speculative; Hartley et al. ${ }^{18}$ did not provide data in their study to allow for an analysis based on injury mechanism).

Second, the sample size used in some studies may have resulted in a type I error (i.e., false positive conclusion). For example, Butler et al..$^{16}$ evaluated YBT-LQ performance in only 59 collegiate football players. Gonell et al. ${ }^{17}$ reported an association between asymmetry in the posteromedial reach direction and injury in male soccer players; however, the sample in that study was 74 . There have been no follow-up studies to date validating these findings. Recent studies, consisting of larger sample sizes, have failed to identify an association between scores and injury. ${ }^{19,20,22}$

Third, YBT-LQ test modifications or performing the "Y" on a SEBT grid may affect the findings of a study. For example, Hartley et al. reported an association between a shorter anterior reach score and ankle sprain injury. ${ }^{18}$ However, Hartley et al. required the athletes to maintain their hands on their hips during performance of the test. ${ }^{18}$ This is a modification from the testing protocol as described by Plisky et al. ${ }^{11}$ Clinicians who screen athletes applying the cutoff score from Hartley et al. ${ }^{18}$ may do so incorrectly if they use the testing protocol described by Plisky et al. ${ }^{11}$ The SEBT inspired the creation of the YBT. One might assume that performance during the SEBT is similar to performance of the YBT. Plisky et al. originally reported an association between SEBT performance and injury in high school BB players. ${ }^{12}$ Subsequent research utilizing the SEBT in the "Y" pattern has found associations between scores and injury in football players, netball athletes, and college-aged individuals. ${ }^{13,31,32}$ However, clinicians should be advised to not assume that the two tests are identical. Athletes demonstrate different postural control strategies when performing the two tests. ${ }^{33,34}$ (Note: Even though the aforementioned studies ${ }^{13,30,31}$ evaluating the ability of the SEBT to discriminate injury risk found significant associations between scores and injury, these studies included contact injuries in the statistical analysis.)

The YBT-LQ does not appear to be effective at discriminating injury risk in athletic populations. However, for athletic trainers and other sports medicine professionals, the YBT-LQ can be used clinically to track improvements in balance after a sports conditioning program, evaluate the severity of an injury, or to quantify improvements in dynamic balance during clinical rehabilitation. Benis et al. ${ }^{35}$ used the YBT-LQ test to evaluate improvements in postural control in elite female BB players who completed an 8 -week body-weight neuromuscular training program. Ryu et al. ${ }^{36}$ reported anterior reach asymmetry was greater in injured professional baseball players when compared to uninjured counterparts. The YBT-LQ has been used during clinical rehabilitation to track changes in balance in athletes post ACL reconstruction. ${ }^{37}$

There are strengths and weaknesses to this study that should be addressed. A strength of the study is that it had a large sample size for the total population. The sample sizes, per sex, can also be viewed as a strength. The sample sizes, per sex, were larger than some of the prior studies that reported an association between injury and preseason scores. ${ }^{16,17}$ Another strength is the use of an $\mathrm{OD}$ of an injury that was restricted to noncontact time-loss LQ injuries. This is also the first study to our knowledge that analyzed YBT-LQ scores prospectively in a D-III collegiate population. 
Even though this sample utilized a heterogeneous population, a weakness of this study is that it did not include athletes from all varsity-level sports. While the authors do not feel that the inclusion of athletes from other sports would have changed the results, it is worth noting.

\section{Conclusion}

Preseason YBT-LQ scores in a heterogeneous population of D-III collegiate athletes or in a population of D-III male athletes were not associated with a sport-related LQ noncontact time-loss injury. There were four reach scores that were associated with a greater risk of injury in female athletes; however, this finding should be viewed with caution and is likely the result of the sample. This study adds to a growing body of literature demonstrating that the YBT-LQ does not discriminate injury risk in athletes.

\section{References}

1. National Collegiate Athletic Association. Division III 2018-19 Facts and Figures. https://ncaaorg.s3.amazonaws.com/about/d3/ 2018-19D3_FactandFigures.pdf. Accessed December 28, 2018.

2. National Collegiate Athletic Association. Does Athletics Enhance the Division III College Experience? 2014. http://www.ncaa.org/sites/ default/files/DIII_Extra_Point_201404.pdf. Accessed December 28, 2019.

3. Powell JW, Dompier TP. Analysis of injury rates and treatment patterns for time-loss and non-time-loss injuries among collegiate student-athletes. J Athl Train. 2004;39(1):56-70. PubMed ID: 15085213

4. Franklin A, Panchik D. Injuries and the quality of life of collegiate athletes: a pilot study. Internet J Allied Health Sci Pract. 2010;8(4); $1-9$.

5. Freedman KB, Glasgow MT, Glasgow SG, Bernstein J. Anterior cruciate ligament injury and reconstruction among university students. Clin Orthop Relat Res. 356, 1998;(356):208-212. doi:10.1097/ 00003086-199811000-00028

6. Harris LL. Integrating and analyzing psychological and stage theories to challenge the development of the injured collegiate athlete. $J$ Athl Train. 2003;38(1):75-82. PubMed ID: 16558677

7. Johnston LH, Carroll D. The psychological impact of injury: effects of prior sport and exercise involvement. $\mathrm{Br} J$ Sports Med. 2000;34(6):436-439. PubMed ID: 11131231 doi:10.1136/bjsm.34. 6.436

8. Kilpatrick M, Hebert E, Bartholomew J. College students' motivation for physical activity: differentiating men's and women's motives for sport participation and exercise. J Am Coll Health. 2005;54(2):87-94. PubMed ID: 16255320 doi:10.3200/JACH.54.2.87-94

9. Perna FM, Antoni MH, Baum A, Gordon P, Schneiderman N. Cognitive behavioral stress management effects on injury and illness among competitive athletes: a randomized clinical trial. Ann Behav Med. 2003;25(1):66-73. PubMed ID: 12581938 doi:10.1207/ S15324796ABM2501_09

10. Selby R, Weinstein HM, Bird TS. The health of university athletes: attitudes, behaviors, and stressors. J Am Coll Health. 1990;39(1):1118. PubMed ID: 2365926 doi:10.1080/07448481.1990.9936208

11. Plisky PJ, Gorman PP, Butler RJ, Kiesel KB, Underwood FB, Elkins B. The reliability of an instrumented device for measuring components of the star excursion balance test. $N$ Am J Sports Phys Ther. 2009;4(2):92-99. PubMed ID: 21509114
12. Plisky PJ, Rauh MJ, Kaminski TW, Underwood FB. Star excursion balance test as a predictor of lower extremity injury in high school basketball players. J Orthop Sports Phys Ther. 2006;36(12):911-919. PubMed ID: 17193868 doi:10.2519/jospt.2006.2244

13. Gribble PA, Hertel J, Plisky P. Using the star excursion balance test to assess dynamic postural-control deficits and outcomes in lower extremity injury: a literature and systematic review. J Athl Train. 2012;47(3):339-357. PubMed ID: 22892416 doi:10.4085/10626050-47.3.08

14. Hertel J, Braham RA, Hale SA, Olmsted-Kramer LC. Simplifying the star excursion balance test: analyses of subjects with and without chronic ankle instability. J Orthop Sports Phys Ther. 2006;36(3): 131-137. PubMed ID: 16596889 doi:10.2519/jospt.2006.36.3.131

15. Smith CA, Chimera NJ, Warren M. Association of y balance test reach asymmetry and injury in division I athletes. Med Sci Sports Exerc. 2015;47(1):136-141. PubMed ID: 24870573 doi:10.1249/ MSS.0000000000000380

16. Butler RJ, Lehr ME, Fink ML, Kiesel KB, Plisky PJ. Dynamic balance performance and noncontact lower extremity injury in college football players: an initial study. Sports Health. 2013;5(5):417422. PubMed ID: 24427412 doi:10.1177/1941738113498703

17. Gonell AC, Romero JA, Soler LM. Relationship between the y balance test scores and soft tissue injury incidence in a soccer team. Int J Sports Phys Ther. 2015;10(7):955-966. PubMed ID: 26673848

18. Hartley EM, Hoch MC, Boling MC. Y-balance test performance and BMI are associated with ankle sprain injury in collegiate male athletes. J Sci Med Sport. 2018;21(7):676-680. PubMed ID: 29102301 doi:10. 1016/j.jsams.2017.10.014

19. Lai WC, Wang D, Chen JB, Vail J, Rugg CM, Hame SL. Lower quarter Y-balance test scores and lower extremity injury in NCAA division i athletes. Orthop J Sports Med. 2017;5(8):2325967117723666. PubMed ID: 28840153 doi:10.1177/2325967117723666

20. Wright AA, Dischiavi SL, Smoliga JM, Taylor JB, Hegedus EJ. Association of lower quarter y-balance test with lower extremity injury in NCAA Division 1 athletes: an independent validation study. Physiotherapy. 2017;103(2):231-236. PubMed ID: 27665043 doi:10.1016/j.physio.2016.06.002

21. Stiffler MR, Bell DR, Sanfilippo JL, Hetzel SJ, Pickett KA, Heiderscheit BC. Star excursion balance test anterior asymmetry is associated with injury status in division I collegiate athletes. J Orthop Sports Phys Ther. 2017;47(5):339-346. PubMed ID: 28355980 doi:10.2519/jospt.2017.6974

22. Brumitt J, Nelson K, Duey D, Jeppson M, Hammer L. Preseason y balance test scores are not associated with noncontact time-loss lower quadrant injury in male collegiate basketball players. Sports. 2018; 7(1):4. doi:10.3390/sports7010004

23. Walbright PD, Walbright N, Ojha H, Davenport T. Validity of functional screening tests to predict lost-time lower quarter injury in a cohort of female collegiate athletes. Int J Sports Phys Ther. 2017;12(6): 948-959. PubMed ID: 29158956 doi:10.26603/ijspt20170948

24. Brumitt J, Patterson C, Dudley R, Sorenson E, Hill G, Peterson C. Comparison of lower quarter $\mathrm{Y}$ balance test scores for female collegiate volleyball players based on competition level, position, and starter status. Int J Sports Phys Ther. 2019;14(3):415-423.

25. Brumitt J, Heiderscheit BC, Manske RC, Niemuth PE, Rauh MJ. Lower extremity functional tests and risk of injury in division iii collegiate athletes. Int J Sports Phys Ther. 2013;8(3):216-227. PubMed ID: 23772338

26. Brumitt J, Wilson V, Ellis N, Petersen J, Zita CJ, Reyes J. Preseason lower extremity functional test scores are not associated with lower quadrant injury- a validation study with normative data on 395 
division iii athletes. Int J Sports Phys Ther. 2018;13(3):410-421. PubMed ID: 30038827 doi:10.26603/ijspt20180410

27. Nouni-Garcia R, Carratala-Munuera C, Orozco-Beltran D, LopezPineda A, Asensio-Garcia MR, Gil-Guillen VF. Clinical benefit of the FIFA 11 programme for the prevention of hamstring and lateral ankle ligament injuries among amateur soccer players. Inj Prev. 2018; 24(2): 149-154. PubMed ID: 28642247 doi:10.1136/injuryprev2016-042267

28. van der Horst N, Smits DW, Petersen J, Goedhart EA, Backx FJ. The preventative effect of the Nordic hamstring exercise on hamstring injuries in amateur soccer players: a randomized controlled trial. Am J Sports Med. 2015;43(6):1316-1323. PubMed ID: 25794868 doi:10. $1177 / 0363546515574057$

29. Silvers-Granelli HJ, Bizzini M, Arundale A, Mandelbaum BR, Snyder-Mackler L. Does the FIFA 11+ injury prevention program reduce the incidence of acl injury in male soccer players? Clin Orthop Relat Res. 2017;475(10):2447-2455. PubMed ID: 28389864 doi:10. 1007/s11999-017-5342-5

30. Dargo L, Robinson KJ, Games KE. Prevention of knee and anterior cruciate ligament injuries through the use of neuromuscular and proprioceptive training; an evidence-based review. J Athl Train. 2017;52(12):1171-1172. PubMed ID: 29172648 doi:10.4085/ $1062-6050-52.12 .21$

31. de Noronha M, Franca LC, Haupenthal A, Nunes GS. Intrinsic predictive factors for ankle sprain in active university students: a prospective study. Scand J Med Sci Sports. 2013;23(5):541-547. PubMed ID: 22260485
32. Attenborough AS, Sinclair PJ, Sharp T, et al. The identification of risk factors for ankle sprains sustained during netball participation. Phys Ther Sport. 2017;23:31-36. PubMed ID: 27665248 doi:10.1016/j. ptsp.2016.06.009

33. Coughlan GF, Fullam K, Delahunt E, Gissane C, Caulfield BM. A comparison between performance on selected directions of the star excursion balance test and the y balance test. J Athl Train. 2012; 47(4):366-371. doi:10.4085/1062-6050-47.4.03

34. Fullam K, Caulfield B, Coughlan GF, Delahunt E. Kinematic analysis of selected reach directions of the star excursion balance test compared with the y-balance test. $J$ Sport Rehabil. 2014; 23(1):27-35. PubMed ID: 23945793 doi:10.1123/JSR.2012-0114

35. Benis R, Bonato M, La T orre A. Elite female basketball players' body-weight neuromuscular training and performance on the y-balance test. J Athl Train. 2016;51(9):688-695. PubMed ID: 27824252 doi:10.4085/1062-6050-51.12.03

36. Ryu CH, Park J, Kang M, et al. Difference in lower quarter Y-balance test with player position and ankle injuries in professional baseball players. J Orthop Surg. 2019;27(1):230949901983242. doi:10.1177/ 2309499019832421

37. Hallagin C, Garrison JC, Creed K, Bothwell JM, Goto S, Hannon J. The relationship between pre-operative and twelve-week postoperative $y$-balance and quadriceps strength in athletes with an anterior cruciate ligament tear. Int $J$ Sports Phys Ther. 2017;12(6):986-993. PubMed ID: 29158959 doi:10.26603/ ijspt 20170986 